\title{
The Relationship between Assessment Method and Learning Approach
}

\author{
Qu Zhao \\ School of Foreign Language ,Anhui Sanlian University, hefei 230000, China \\ niczhaov6@163.com
}

Keywords: Assessment Method; Learning Approach; Learning Motivation

\begin{abstract}
Quantitative and qualitative analysis revealed that students took different learning approaches for assessments in different nature according to their understanding of the abilities being evaluated. Assessment type such as presentation and essay were more likely to promote the adoption of deep approach while objective test tended to lead to the use of surface approach, which was not desirable in tertiary studies. Therefore, proper assessment types should be employed to encourage the students to adopt deep learning approach in their learning.
\end{abstract}

\section{Introduction}

So far, the various kinds of courses in formal education are taking advantage of various methods to assess the learning outcomes of learners. In the past, liberal arts teaching in colleges mainly depend on mid-term exams, final term exams and other assessment methods while now many colleges also add usual performance to total scores in order to fully examine students' learning outcomes. However, it is a question worth pondering that whether all assessment methods can correctly guide students to use appropriate learning approach or learning strategies to deal with various forms of assessment as well as meet the goals set by the syllabus. This research aims to investigate the relationship between different assessment methods and learning approaches and the influence on them.

\section{Research on Learning Approaches}

Overseas research on learning approaches began in the mid 1970s. The study showed that different learning approaches students adopted could result in different results which will decide the quality of learning. In earlier study of Marton and Saljo(1976), learning approach refers to learning process students adopted that will achieve the learning goal. Later Biggs (1987) in his discussion stated that it was a learning method that students adopted in a particular learning environment. And the learning approach consists of two aspects: the kind of learning approach learners adopt and learners' motivation to do so. Related research (Marton \& Saljo, 1976; Watkins, 1983) found that the three main learning approaches: surface approach to learning, deep approach to learning and strategic approach to learning. Students who adopt the surface approach to learning have no intrinsic motivation to learn and they only want to obtain the certificate by passing the exam.

In view of the backwash effect of exam, most students will learn the knowledge and cognitive abilities that they are required to prove. (Fransson, 1977:245) From this sense, it is the assessment methods that determine what students learn, how much they learn and how they learn. Currently there are two main assessment methods for liberal arts courses of Chinese Universities: final exams and essays, which embody the characteristic of deep approach to learning. However, final exams usually require students to remember factual information in courses and then reproduce in them if final exams mainly consist of objective choices and blank fillings.

As a result, students would get high scores as long as they tick or fill in correctly even if they don't understand the knowledge. Biggs (1993) holds that the learning process involves three levels of cognitive level: low cognitive learning means learning the facts and information for the purpose 
of accurately reproducing the material; high cognitive learning involves sorting and summarizing the contents to form a conceptual understanding of learning; and metastatic learning means applying the existing knowledge and understanding to the new environment. Up until now, foreign researches lay more emphasis on revealing the relationship between objective tests and surface approach to learning, while paying less attention on studying the identical course. Tang (1992) and Scouller (1998) found that students tended to adopt surface approach to learning when preparing for exams; however, they adopted deep approach to learning when preparing for essays.

\section{Research Design}

\subsection{Research Issue}

This research is to explore the following questions: 1) Whether students use different learning approach to cope with different assessment methods; 2) How they look at these assessment methods; 3) Which methods they prefer to choose and why; 4) If there exist any correlations between learning approaches, students' opinion towards assessment methods, their elective tendency and learning outcomes; 5) If there show differences of realization approach between male and female students.

\subsection{Research Methods}

\subsubsection{Subjects and Research Tools}

Research is scheduled to conduct in the first week of term, in which 210 English majors in grade three will participate. Subjects are required to fill in a questionnaire concerning one of their optional cultural courses. In addition to basic information about the subjects, the questionnaire consists of three parts. The first part is composed of 30 narrations, in which 15 narrations describe surface approach to learning and the rest 15 narrations describe deep approach to learning. After each presentation, there are three kinds of assessment methods: presentation, term paper and final exam. When preparing for their own assignments or examinations, students were asked to mark their choice on the 5-point Likert Scale ranging from strongly agree (5 points) to strong disagree (1 point). The second part is composed of 14 narrations, in which 7 narrations describe low-level skill and ability, and 7 narrations describe high-level cognitive processing capability.

The third part requires students to show their preference for the three assessment methods and state brief reasons. Questionnaire should be finished in class for about 30 minutes. Excluding incomplete ones, we have gathered 190 answer sheets for statistics, in which 80 male students and 11 female participate.

\subsubsection{Data Analysis}

All the answers in the first and second part as well as objective question answers are inputted into the computer, using social science statistics software SPSS for calculations. The third part briefly introduces reasons, which adopt qualitative analysis methods. 


\section{Results and Discussion}

\subsection{Methods Students Adopted towards Different Assessment Methods}

Table 1 Methods students used towards different assessment methods

(Mean standard deviation and variance analysis)

\begin{tabular}{|l|l|l|l|l|l|l|l|l|}
\hline \multirow{2}{*}{ Approach variable } & \multicolumn{9}{|l}{ Presentation } & \multicolumn{7}{l|}{ OBJ test } \\
\cline { 2 - 10 } & $\mathrm{M}$ & $\mathrm{SD}$ & $\mathrm{M}$ & $\mathrm{SD}$ & $\mathrm{M}$ & $\mathrm{SD}$ & $\mathrm{F}$ & $\mathrm{P}$ \\
\hline Surface motives & 2.68 & 0.59 & 2.87 & 0.65 & 3.72 & 0.81 & 75.64 & 0.000 \\
\hline Surface strategies & 2.42 & 0.51 & 2.35 & 0.47 & 3.78 & 0.57 & 502.35 & 0.000 \\
\hline lower abilities & 2.53 & 0.61 & 2.52 & 0.68 & 4.14 & 0.83 & 394.31 & 0.000 \\
\hline Deep motives & 3.62 & 0.68 & 3.72 & 0.76 & 2.45 & 0.76 & 160.54 & 0.000 \\
\hline Deep strategies & 3.79 & 0.53 & 3.95 & 0.51 & 2.10 & 0.55 & 702.48 & 0.000 \\
\hline higher abilities & 3.88 & 0.52 & 4.13 & 0.64 & 2.08 & 0.57 & 807.21 & 0.000 \\
\hline
\end{tabular}

$\mathrm{N}=190$, OBJ test $=$ objective test, $\mathrm{M}=$ mean, $\mathrm{SD}=$ standard deviation, $\mathrm{F}=$ variance analysis statistic, $\mathrm{P}=$ probability

Table 1 reveals that subjects believe assessment methods such as presentations and essays examine high cognitive ability that may induce their intrinsic motivation, thus they would adopt deep approach to learning in many cases. However, subjects believe that objective question examines low cognitive ability; therefore they would adopt surface approach to learning for they generally have surface strategy. Analysis of variance reveals significant difference $(\mathrm{P}<0.000)$, which coincides with findings of overseas study (Tang, 1992; Scouller, 1998). Subjects realize that different assessment methods require different levels of cognitive ability, thus with which they adopt different learning approach to deal. They believe that objective tests based on text knowledge aims at examining students' low cognitive ability, and therefore they will pass the exam as long as they recite the text points even without thorough understanding. Meanwhile, they hold that presentations and essays lay much emphasis on their high cognitive ability such as understanding, analysis, judgment, and applications. Statistics found that subjects' understanding towards different assessment methods play a key role in determining their different learning approaches. Related analysis showed that presentation performance had some correlation with their perception for high cognitive ability ( $\mathrm{r}=0.3, \mathrm{P}<0.001)$.

\subsection{Selective Preference or Assessment Methods}

Table 2 Selection for Three Types of Assessment Methods

\begin{tabular}{|l|l|l|}
\hline \multicolumn{1}{|c|}{ Type of Assessment } & Preference & Percentage (\%) \\
\hline presentation & 130 & 68.4 \\
\hline term paper & 98 & 51.6 \\
\hline OBJ test & 23 & 14.5 \\
\hline
\end{tabular}

Subjects can select one, two, even three types according to their true will. Table 3 shows that 130 students prefer presentation as the assessment measure; more than half students select essay, however, only 23 students choose objective test, accounting for $14.5 \%$. As for presentation, subjects believe that "lectures can better reflect all aspects of students' ability. In terms of preparing materials, students will start with textbooks, and then turn to find relevant information through various channels for analysis and screening. When preparing PPT, they will consider how to present the content briefly and to the point. This assessment measure will not only help students to further study the issue and learn logical analysis, but also a challenge for writing skills. In addition, it will be beneficial to develop students' ability to independently explore and expand their horizons, which will be helpful in future academic research. As for objective tests, few subjects who choose this 
assessment measure believe "you can pass the exam by reciting textbooks even if you don't attend class for the whole term". However, those who hold the opposite idea think that "objective tests are so rigid that they only require good memory, and they are nonsense". In summary, we have reason to believe that the vast majority of junior students hope to go through a complete research process and improve their ability in asking questions, analyzing questions and solving questions, rather than simply remember some factual information.

\subsection{Evaluation Measures and Learning Outcomes}

Table 3 Selection of Assessment Methods and Score Analysis

\begin{tabular}{|l|l|l|l|l|}
\hline Preference & PS & ES & TS & P \\
\hline presentation & 1 & $0.468 * *$ & 0.158 & 0.00 \\
\hline essay & $0.439 * *$ & 1 & $0.268 *$ & $0.01 / 0.05$ \\
\hline OBJ test & 0.064 & -0.144 & 1 & 0.05 \\
\hline
\end{tabular}

Table 3 reveals that the scores of students who select presentation and essay are positively correlated $(\mathrm{r}=0.468 ; \mathrm{P}<0.000)$, showing statistical significance. However, the selection and objective test have no correlation. The results suggest that if students who like presentation get better presentation scores, they are likely to get better essay scores. There shows no correlation between their presentation scores and essay scores $(\mathrm{r}=0.158)$. The essay scores for students who select presentation have positive correlation with their presentation scores $(r=0.439)$, which was statistically significant $(\mathrm{P}<0.01)$, while there has correlation between test scores $(\mathrm{r}=0.268, \mathrm{P}<0.05)$. The analysis suggests that students who get better essay scores are likely to have better presentation and essay scores. However, the scores of students who select tests have no correlation with the two former scores $(r=0.064)$, moreover, the scores show negative correlation with presentation scores $(r$ $=-0.144)$.

\section{Conclusion}

Statistical analysis of the results of the above research may answer our questions: 1) Subjects adopt different approaches in response to the three types of assessment methods. They tend to adopt surface strategy for objective tests while they adopt deep strategy for presentations and essays; 2) Subjects believe that objective tests examine students' low cognitive ability while presentations and essays examine students' high cognitive ability; 3)The selection of subjects who choose presentations and essays has correlation with learning outcomes, while the selection of who choose objective tests has no correlation with learning outcomes. Studies show that presentations and essays writing can stimulate students' deep motivation, therefore, the frequent use of deep strategy in learning can be considered as the primary assessment method in liberal arts teaching. In conclusion, college teaching should not only put emphasis on the adoption of assessment methods, but also encourage and develop students’ high cognitive ability and innovation ability.

\section{References}

[1]Biggs, J.B. Student Approaches to Learning and Studying [M]. Hawthorn, Vic.: Australian Council for Educational Research, 1987.

[2]Fransson, A. On qualitative differences in learning. IV-effects of intrinsic motivation and extrinsic test anxiety on process and outcome [J]. British Journal of Educational Psychology, 1977, 47:244 -257.

[3]Marton, F\&Saljo, R .On qualitative differences in learning-I: Outcome and process [J]. British Journal of Educational Psychology, 1976, 46:4 -11.

[4] Paine, L .Teaching and modernization in contemporary China [A]. In Hayhoe, R. (ed.). Education and Modernization: the Chinese Experience [C]. Pergamon Press. Oxford .1992. 
[5] Scouller, $\mathrm{K}$.The influence of assessment method on students' learning approaches: Multiple choice question examination versus assignment essay [J]. Higher Education, 1998, 35:453 -472. 